Journal of Southeast Asian

\title{
Appendix F: Focus Group Summary of the Vietnamese Student Association
}

Qua Thi Nguyen

University of California at Santa Barbara, qui.thi.nguyen@gmail.com

\section{Recommended Citation}

Nguyen, Qua Thi (2011) "Appendix F: Focus Group Summary of the Vietnamese Student Association," Journal of Southeast Asian American Education and Advancement. Vol. 6 : Iss. 1, Article 7.

DOI: $10.7771 / 2153-8999.1023$

Available at: https://docs.lib.purdue.edu/jsaaea/vol6/iss1/7

This document has been made available through Purdue e-Pubs, a service of the Purdue University Libraries. Please contact epubs@purdue.edu for additional information.

This is an Open Access journal. This means that it uses a funding model that does not charge readers or their institutions for access. Readers may freely read, download, copy, distribute, print, search, or link to the full texts of articles. This journal is covered under the CC BY-NC-ND license. 


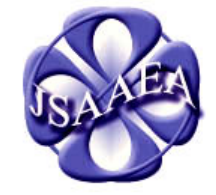

Volume 6 (2011)

\section{Journal of Southeast Asian American}

Education \& Advancement

WWw.JSAAEA.org
A peer-reviewed

\section{Southeast Asian American Education 35 Years After Initial Resettlement: Research Report and Policy Recommendations}

Conference Report of the National Association for the Education and Advancement of Cambodian, Laotian, and Vietnamese Americans

\section{APPENDIX F}

\section{Focus Group Summary of the Vietnamese Student Association}

\section{Qua Thi Nguyen University of California at Santa Barbara}

\section{Southeast Asian Student Education (K-12): Access, Assessment, and Accountability}

From grades $\mathrm{K}-12$, the participants agreed that school was enjoyable to the extent that they were able to develop socially as they met new people and spent most of their time with their friends. As the participants advanced to high school, their desire for learning decreased with the increasing number of unqualified and unmotivated teachers who were not able to assist all the students due to the overpopulated classrooms. One student stated that some teachers graded unfairly and handed out an unbearable amount of homework while another student argued that some teachers were easy to manipulate into giving less homework or giving better grades.

Since most of the students were from Hispanic communities, discrepancies between Asians and Southeast Asians did not exist. In the words of one participant, "Asian is Asian." In contrast, another student from San Francisco described his demographic area as mainly white with no distinct Asian population where Asians were treated as equals. When it comes to academics, Asians in the participant's schools did very well. However, one student pointed out how statistics show that Cambodians did not perform as well as other Asian students but she never witnessed it. Surprisingly, none of the students could recall any Southeast Asian teachers or administrators working in their schools. One student did confuse his average physical education teachers for being Southeast Asian even though he was actually Chinese. When asked if the students would prefer to have more Southeast

\section{()}

SORERIIGHISRESERVED Readers are free to copy, display, and distribute this article, as long as the work is attributed to the author(s) and the Journal of Southeast Asian American Education \& Advancement, it is distributed for noncommercial purposes only, and no alteration or transformation is made in the work. More details of this Creative Commons license are available at http://creativecommons.org/licenses/by-nc-nd/3.0/. All other uses must be approved by the author(s) or JSAAEA. 
Asian teachers or administrators, they all agreed that "whoever wants to be a teacher, should be a teacher" aside from their race and ethnicity as long as they can teach.

With English as a second language to these students in the focus group, many of them were categorized as English Language Learners and were placed in ESL until they proved their proficiency in English. One student strongly felt that people were discriminated against and wrongfully categorized even though they were fluent in English because they selected English as a second language on their school applications. Another student shared her experience of being placed in ESL when first entering school, but taken out of the program after only two months because she was already fluent in English. With English as a second language, many of these students found themselves as translators for students, teachers, and even their parents.

This language barrier between these students and their parents is the greatest challenge they have had to face as a Vietnamese American who cannot completely acculturate to either Vietnamese or American culture without losing communication in the process. Although one student argued that the school curriculum should not be changed and would not change for the minorities, the other students felt that a community center or at least one translator on-site should be available for students and parents who are having trouble. This would not only bridge the gap between the parents and their students-but Vietnamese and Vietnamese-Americans as well.

In the school curriculum, Southeast Asian history and culture is nonexistent. Clubs and organizations were the only way students could learn about Vietnamese history and culture, but many students did not bother to join. When asked whether Southeast Asian history and culture should be added to the school curriculum, the participants engaged in a huge debate. On one side, one participant believed that the majority of the students think there is no point in learning about other people's culture. In contrast, other participants felt that knowledge of other cultures was crucial since America is a very diverse and global country. In response, another participant suggested that the K-12 system should continue to teach broader topics while college courses should continue to teach more specific topics. That way, students can decide whether they would like to learn about the Southeast Asian culture.

The participants negatively responded to the state tests required to take in school. They felt like the tests did not measure a student's full potential and was a waste of time. The state tests were not taken seriously and some students even failed it purposely to prove a point. As much as the students despised these state tests, they knew that these tests helped their school gain government funding as an incentive to do well. The main critique of these state tests was actually directed towards where the funding was going. The participants felt that government funding should not be used as an incentive because it keeps the students that need resources at a lower disadvantage. One participant suggests that the government needs to access students on their individual growth rather than their test scores since it does not take those who are less fortunate or those with low-quality teachers into account. Other participants thought the tests were beneficial guidelines that kept teachers are accountable for their student's learning. The participants felt like the tests were easy 
enough to pass, but knew some students who did not pass because they were negatively influenced or did not care to pass the state tests.

The policy changes suggested to address these K-12 issues mainly dealt with the quality of the teachers. The participants suggested that more funding should be used to lower the class sizes to ensure a better learning environment for the students where they can get the help they need. The participants would also like the administration to strictly monitor the teachers forcing them to have better agendas. Last but not least, the students suggested paying the teachers more to give them more motivation and incentive to teach since teaching is becoming a job that requires a lot of work; thus, making their job more rewarding and ensuring the quality of the teachers.

\section{Southeast Asian Language and Culture Programs}

As stated in the previously, the participants were only fluent enough to speak to their families in Vietnamese but they cannot read nor write. One of the participants could not speak, read, or write in Vietnamese; his only way of communicating with his parents was through body language and minimal knowledge of the language. This participant was the only one who admitted to being "white-washed" while the other participants felt a strong connection with their Vietnamese language, culture, and identity. The participants felt that knowing their language is definitely crucial for their connection to their family, culture, and community as a whole, yet it can be very subjective. If Vietnamese language classes were offered in high school or college, many of the participants would have taken it. One student pointed out that even in a very dense Vietnamese community like Orange County, only a handful of Vietnamese classes are available so there are less expectations of having it in colleges especially with the budget cuts.

As members of the Vietnamese Student Association at the University of California, Santa Barbara, it is harder to represent their Vietnamese culture when they cannot communicate with their parents to obtain a full understanding of their background and culture. Although Vietnamese Sunday schools were available at churches and temples for no school credit, many of the participants did not take advantage of this opportunity. Those who did attend Vietnamese Sunday school found it ineffective since they could not see the benefit of it at a young age. One student suggested that Vietnamese language classes should be available in schools to give it an educated value so students would extra incentive to study and know the language. The participants all agreed that more language programs are needed in schools since students would not be able to grasp the language if they only practice once every week. In the next few generations, the participants believed the Vietnamese language would be forgotten entirely since "time separates you from your time and culture". Also, our society is getting more multi-racial which will further dilute our language.

Currently, the University of California, Santa Barbara cannot open up departments because of the budget cuts. If Vietnamese language classes were offered, people would take it. We have petitioned for Vietnamese language and ethnic classes before, but have been unsuccessful in getting the classes established. Also, the Education Abroad Program for Vietnam was also cut this year so the Vietnamese students at UCSB has no other 
connections to our culture and language except through our Vietnamese Student Association. In order to fix the issue of language programs, the government needs to put more money into the schools. Also, it is crucial for the students to know exactly where their tuition is going so the allocation of money should be transparent to the faculty, staff, and students as well.

\section{Southeast Asian American Higher Education Access and Opportunities}

As Southeast Asian students are preparing for college, they face many challenges and obstacles. One participant claimed that he faced a lack of financial support amongst Asians, in general, which is one of the biggest obstacles a Southeast Asian student tends to face. Another participant states that some colleges have been cutting back on the acceptance rate of Asians who go to college because the campus already consists of too many people of Asian descent. In this way, the colleges have been undercutting Asian students who should be able to achieve higher education. Even the sport's scholarships and the recruitment process are discriminatory against Asians based on stereotypes. Some participants believed that college admissions should not be based on race and should only be based on merits. However, this would be unfair to the students from low-income areas that have less resources and educational opportunities.

As far as parental support goes, the participants' parents have given them plenty of support and encouragement because Southeast Asian parents want their children to achieve a higher education. In contrast, one of the participants has witnessed Southeast Asian parents who discourage their children from achieving a higher education. These parents tend to do so because they want their children to inherit the family business. While in college, these participants have faced a lack of resources and self-initiative. One of the biggest challenges today is the availability of courses. Because of the budget cuts, courses have been cancelled and classes have been filling up so it will take more time for the college students to graduate. In addition, junior colleges have also been filling up so those who want to pursue a college degree without going straight to a four-year college is finding it difficult to even enroll.

Many Southeast Asian students and students, in general, have dropped out of school due to a lack of parental support which comes down to family ideals and values. Other reasons for dropping out of college are the lack of motivation in oneself or simply the temporary stability of working instead of gaining a higher education. To prevent these higher education issues, the government and colleges need to provide more accessible resources like college preparations courses or guidance on what to do after they make it into college. The more obvious policy change is to put more money into the school and outreach programs that help high school students experience the rigorous college course load.

\section{Southeat Asian American Communities}

The biggest challenges facing our Vietnamese community are finding a balance between being a Vietnamese and an American, our representation in the media, and retaining cultural identity in order to "remember your language, your roots, or know something about your home country even if you haven't been there." Our community continues to face 
negative stereotypes characterized by our society and the exploitation of Southeast Asian workers in nail salons, mechanics, and restaurants. Our Vietnamese community is still discriminated against, but as a part of the Asian population as a while and not Vietnamese just by itself. In order to overcome these challenges, we need to outreach to more students and spread our cultural awareness.

On a brighter note, our Vietnamese community has had many successes. We have more role models to look up to in America and more people achieving higher influential statuses. The government no longer groups Vietnamese together with the Asian category and we have representatives in the House of Representatives, but we still do not have enough. To help address community issues, "we need a more transparent way of seeing what we are voting for and what we are paying for". We also need to come up with more ways to spread cultural awareness in a fun and social environment like the Vietnamese Student Association because more people will retain the information that way. Also we need more representatives to represent our community in the government and, of course, more funding.

\section{About the Author}

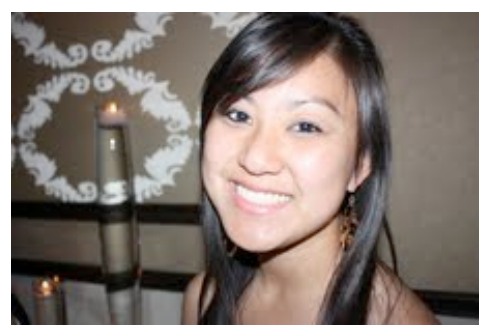

Qua Thi Nguyen was born and raised in Salinas, California. She is currently working towards a bachelor's degree in Sociology with a minor in Education at the University of California, Santa Barbara. She joined the Vietnamese Student Association where she held the positions of Philanthropy Chair, Student Initiated Outreach Program Co-Chair, Intercollegiate Council Member, External Vice President, and Co-President. During her term as Co-President, she was presented with the opportunity to attend the National Conference for NAFEA in Washington, DC as a panelist sparking her desire to obtain a master's degree in Asian American Studies after completing her undergraduate studies. 